\title{
Choice of Site for the Installation of Photovoltaic Solar Power Plants in Senegal: Consequences on Electricity Production
}

\author{
Mactar Faye $^{1,2}$, Ababacar Thiam ${ }^{1,2}$ \\ ${ }^{1}$ Efficiency and Energetic Systems Research Group, Alioune Diop University, Bambey, Senegal \\ ${ }^{2}$ Laboratoire d'Energétique Appliquée, Ecole Supérieure Polytechnique, Université Cheikh Anta Diop, Dakar, Senegal \\ Email: mactar.faye@uadb.edu.sn
}

How to cite this paper: Faye, M. and Thiam, A. (2017) Choice of Site for the Installation of Photovoltaic Solar Power Plants in Senegal: Consequences on Electricity Production. Journal of Power and Energy Engineering, 5, 109-118. https://doi.org/10.4236/jpee.2017.512013

Received: November 14, 2017 Accepted: December 25, 2017 Published: December 28, 2017

Copyright $\odot 2017$ by authors and Scientific Research Publishing Inc. This work is licensed under the Creative Commons Attribution International License (CC BY 4.0).

http://creativecommons.org/licenses/by/4.0/

\section{Open Access}

\begin{abstract}
A theoretical analysis of the electricity production of a photovoltaic solar power plant of $22 \mathrm{MW}$ for different sites in Senegal is presented. The study is carried out in two coastal regions (Dakar and Saint-Louis) and two continental regions (Mbacké and Linguère). This study is done using the RET Screen clean energy project management software climate data. The amount of electricity exported to the grid is calculated for each site. The results show that the climatic conditions of the coastal and continental regions are different from November to June. From July to October, which corresponds to the rainy season in Senegal, the climatic conditions of the coastal and continental regions are similar. The results also show that although the efficiency of photovoltaic modules is better on the coast, electricity production varies little from one site to another. Climate conditions in Senegal therefore have no impact on electricity production.
\end{abstract}

\section{Keywords}

Photovoltaic Solar Power Plant, Climatic Conditions, Electricity Production, Coastal Zone, Continental Zone

\section{Introduction}

The electricity sector faces many challenges. Electricity demand is increasingly important. The electricity consumers aspire for the power supply of reasonable quality at reasonable price. To meet these challenges, it is necessary to plan the electrical infrastructure, energy and technological choices guaranteeing the competitiveness of the Senegalese electricity system, and minimizing the impact on the environment. Thus, Senegal has set itself the goal of diversifying energy 
sources through the introduction of clean energy, to reduce the cost per kilowatt-hour in the long term and to secure the supply of electrical energy in quantity and quality.

In 2014, electricity production in Senegal was estimated at $3729 \mathrm{GWh}$ [1]. Less than $10 \%$ of this production came from the hydroelectric and solar sub-sectors. The government of Senegal has set itself the objective of increasing the share of renewable energies in the energy mix to $20 \%$ by the end of 2017. It therefore plans to install photovoltaic solar power plants on several sites throughout the country.

The production of electricity from a photovoltaic solar power plant depends on the solar radiation of the site but also on the climatic conditions. Several authors have been interested in the impact of climatic conditions such as wind speed, ambient temperature on the temperature of a photovoltaic (PV) module. Mirzaei et al. [2] studied the impact of an air flow on the surface temperature of photovoltaic modules. The results showed that the obstruction of the air flow leads to heating of the photovoltaic modules and that the increase in the air circulation speed leads to a decrease in the surface temperature of the modules. Goverde et al. [3] studied the effect of the position of the module with respect to the direction of the wind on the spatial distribution of the temperature at the surface of a PV module. The results showed that the points close to the leading edge of the module are more cooled than the distant points. This temperature gradient leads to heat exchanges in the module. This negatively affects the production of energy. Zhen Ye et al. [4] have analysed the influencing factors on module temperature of selected photovoltaic (PV) systems in tropical regions. Rooftop material, ventilation, module framing and other environmental conditions have been studied. The authors have shown in order to optimize the performance of PV systems in constantly hot climates such as the tropics; it is paramount to keep PV module temperatures as low as possible. They concluded that locations near lakes, woods and natural reserves are favorable.

All these works show the impact of climatic conditions on the temperature of a PV module. There are many models in the literature that link the temperature of a PV module to the climatic conditions [5]. The temperature of a PV module has a direct influence on the electrical efficiency of the photovoltaic modules. Several authors proposed correlations linking this temperature to the electrical efficiency of PV modules [6]. These correlations show that the electrical efficiency decreases as the temperature of the modules increases. Rahman et al. [7] have shown that when the PV modules are cooled with a heat transfer fluid, the efficiency of the modules increases substantially. However it is well known that the electrical efficiency increases with the irradiation. In the tropical zone, usually when the irradiation increases, the ambient temperature increases, and therefore the temperature of the PV modules increases. It is therefore difficult to know the impact of climatic conditions on electricity production based only on the temperature of the modules. Indeed, the importance of the irradiation can compensate for the losses due to the increase of the temperature of the PV modules. In order not to overestimate the effect of the climatic conditions, the evalu- 
ation of the impact of the effect of the climatic conditions must take into account the irradiation of the installation site of the photovoltaic systems. The objective of this work is to evaluate the impact of climatic conditions on the electrical production of a solar power plant taking into account the irradiation of the implantation site. To achieve this objective, four sites of different climatic conditions are considered and the electricity production of a solar power station is calculated for each of the sites.

\section{Context}

\subsection{Climatic Conditions in Senegal}

The Senegalese territory lies between $12^{\circ} 8$ and $16^{\circ} 41$ north latitude and $11^{\circ} 21$ and $17^{\circ} 32$ west longitude. Senegal covers $196,722 \mathrm{~km}^{2}$. The climate is Sahelian. It has a rainy season and a dry season. The rainy season extends from July to October, the dry season from November to June.

On the coast, the sea brings freshness and the temperatures are of the order of $16^{\circ} \mathrm{C}$ to $30^{\circ} \mathrm{C}$, but in the center and the east of the country, they can reach $41^{\circ} \mathrm{C}$. In this study, two sites located on the coast (coastal zone), Dakar and SaintLouis, and two sites located in the center and the east (continental zone), Mbacké and Linguère, are considered. Table 1 gives the latitude and longitude of the sites.

Figure 1 shows the location of the sites on the map of Senegal.

Table 1. latitude and longitude of the sites.

\begin{tabular}{rcccc}
\hline & Mbacké & Linguère & Dakar & Saint-Louis \\
\hline Latitude & 14.8 & 15.38 & 14.73 & 16.05 \\
Longitude & -15.92 & -15.12 & -17.5 & -16.45 \\
\hline
\end{tabular}

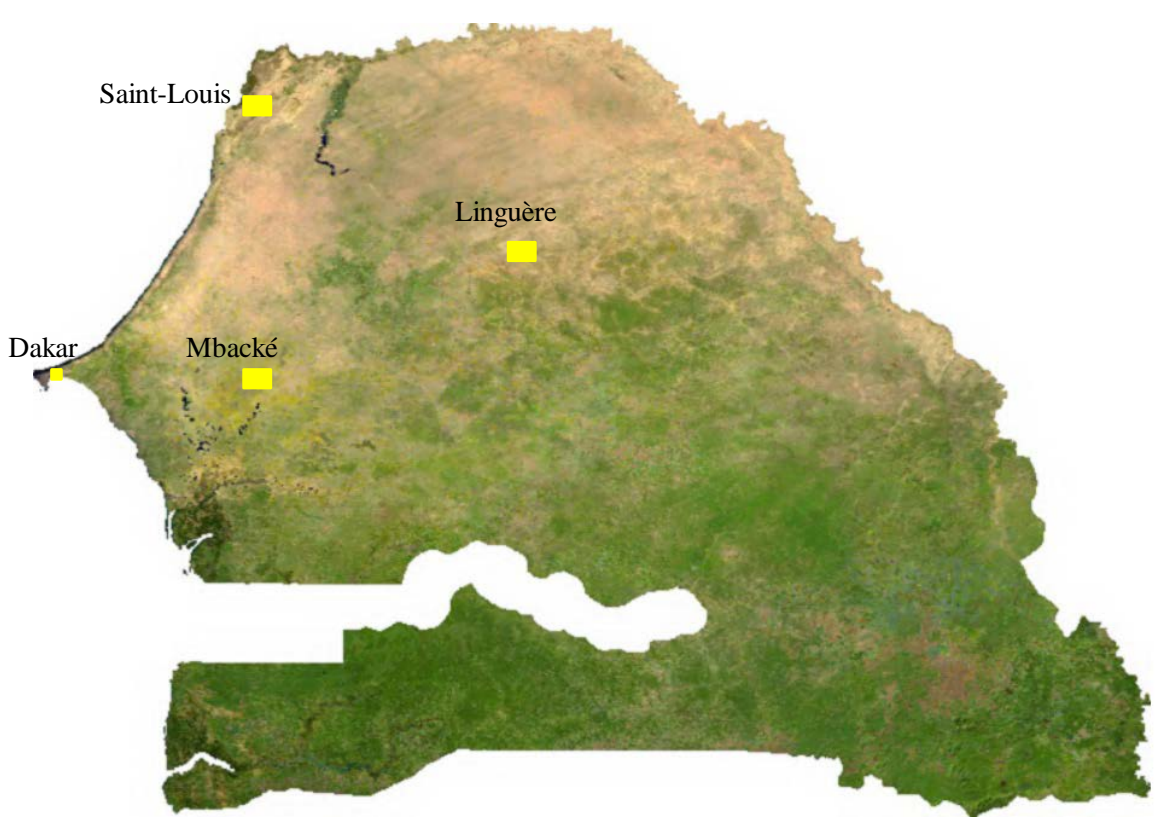

Figure 1. Map of Senegal with the sites studied. 


\subsection{Presentation of the Photovoltaic Solar Power Plant Studied}

The photovoltaic solar power plant studied is located in Malicounda, $84 \mathrm{~km}$ from Dakar, the capital of Senegal. It is the result of a concession contract concluded between the National Electricity Company of Senegal and Solaria Group. This photovoltaic solar power plant with a capacity of $22 \mathrm{MW}$ is connected to the electricity grid. The field of photovoltaic panels occupies an area of $45 \mathrm{hec}-$ tares with 86,000 polycrystalline photovoltaic panels. Senegal being in the northern hemisphere, the panels are oriented towards the south. In this study, the efficiency of photovoltaic panels is $15.75 \%$.

\section{Methodology}

In this study, the electricity production of a solar power plant based on the site of installation is calculated. A site is characterized by its climatic conditions including the ambient temperature, the wind speed and the horizontal daily solar radiation. The relation between these parameters and the temperature of the PV modules is given by the Faiman model [8]

$$
T_{p v}=T_{a}+I_{T} /\left(U_{0}^{\prime}+U_{1}^{\prime} \cdot v_{w}\right)
$$

$T_{a}$ and $V_{W}$ are the ambient temperature and the wind speed, respectively. $I_{T}$ is the plane of array irradiance. $\left(U_{0}^{\prime}, U_{1}^{\prime}\right)$ are empirical coefficients.

In this study, the values of these coefficients are those resulting from the work of Barykina et al. [9]. In their work, Barykina et al. have used measurements from five test sites with different climate conditions. Meteorological data $\left(T_{a}, I_{T}\right.$, $\left.V_{w}\right)$ and outdoor PV module characteristics were measured over at least one year period. Identical sets of different PV modules were installed at each of the sites. All modules are freestanding and south-oriented. The ratio $I_{T} / T_{p v}-T_{a}$ as a function of wind speed is then traced. The intersection of the linear fit with the y-axes gives the value of $U_{0}^{\prime}$ and the slope gives the value of $U_{1}^{\prime}$. Average values over all sites leads to $U_{0}^{\prime}=35.9 \mathrm{~W} /\left({ }^{\circ} \mathrm{Cm}^{2}\right)$ et $U_{1}^{\prime}=4.44 \mathrm{Ws} /\left({ }^{\circ} \mathrm{Cm}^{3}\right)$. Among the sites studied by Barykina et al., the site of Tempe at USA presents the same climate as Senegal (Sub-tropical desert). We therefore make the assumption that the coefficients found in this site can be used for Senegal:

$$
U_{0}^{\prime}=32.12 \mathrm{~W} /\left({ }^{\circ} \mathrm{Cm}^{2}\right) \text { et } U_{1}^{\prime}=4.51 \mathrm{Ws} /\left({ }^{\circ} \mathrm{Cm}^{3}\right)
$$

Knowing the temperature of the PV modules makes it possible to calculate the efficiency of the modules. The expression of the efficiency of the PV modules is given by the expression [10]:

$$
\eta_{p v}=\eta_{S T C} \cdot\left[1-\gamma_{P m} \cdot\left(T_{p v}-25\right)+\delta \cdot \ln \left(I_{T} / 1000\right)\right]
$$

It is then possible to calculate the electrical power supplied by the photovoltaic solar power plant.

$$
P_{m}=P_{m, S T C} \cdot \frac{\eta_{p v}}{\eta_{S T C}} \cdot\left(I_{T} / 1000\right)
$$

where $P_{m, \text { STC }}$ and $\eta_{\text {STC }}$ the peak power and the efficiency of the PV modules 
under standard conditions $\left(I_{T}=1000 \mathrm{~W} / \mathrm{m}^{2}\right.$, air density $\left.1.5, T_{p V}=25^{\circ} \mathrm{C}\right) ; \gamma_{P m}$ is the temperature coefficient for $P_{m}$ and is generally given by the manufacturer, and $\delta$ is the solar irradiation coefficient which is equal 0.11 for polycrystalline modules. $T_{p v}$ is the temperature of the PV module. $I_{T}$ is the solar irradiance.

\section{Description of Climate Data}

In this work, data on the ambient temperature, wind speed and daily solar radiation horizontal of the sites studied are taken from the RET Screen software. The data used is NASA satellite data.

Figure 2 compares the evolution of the ambient temperature of the 4 sites as a function of the month. The results show that from November to June, there is a significant difference between the ambient temperatures of the coastal and continental zones. Ambient temperatures are higher in continental zone than in coastal zone. The temperature difference between the two zones is on average $5^{\circ}$ C. From July to October, temperatures in the coastal and continental zones are similar. This period corresponds to the rainy season. The rainy season significantly decreases the ambient temperatures in the continental zones.

Figure 3 shows the evolution of the wind speed as a function of the month for different sites. The results show that the wind speed is high in Dakar, Saint-Louis and Mbacké. It is relatively weak for Linguère. Wind speed is higher in coastal zone than in continental zone.

Figure 4 shows the evolution of the solar irradiance as a function of the month for different sites. The results show that there is a small gap between the solar irradiance in the coastal zone and that in the continental zone.

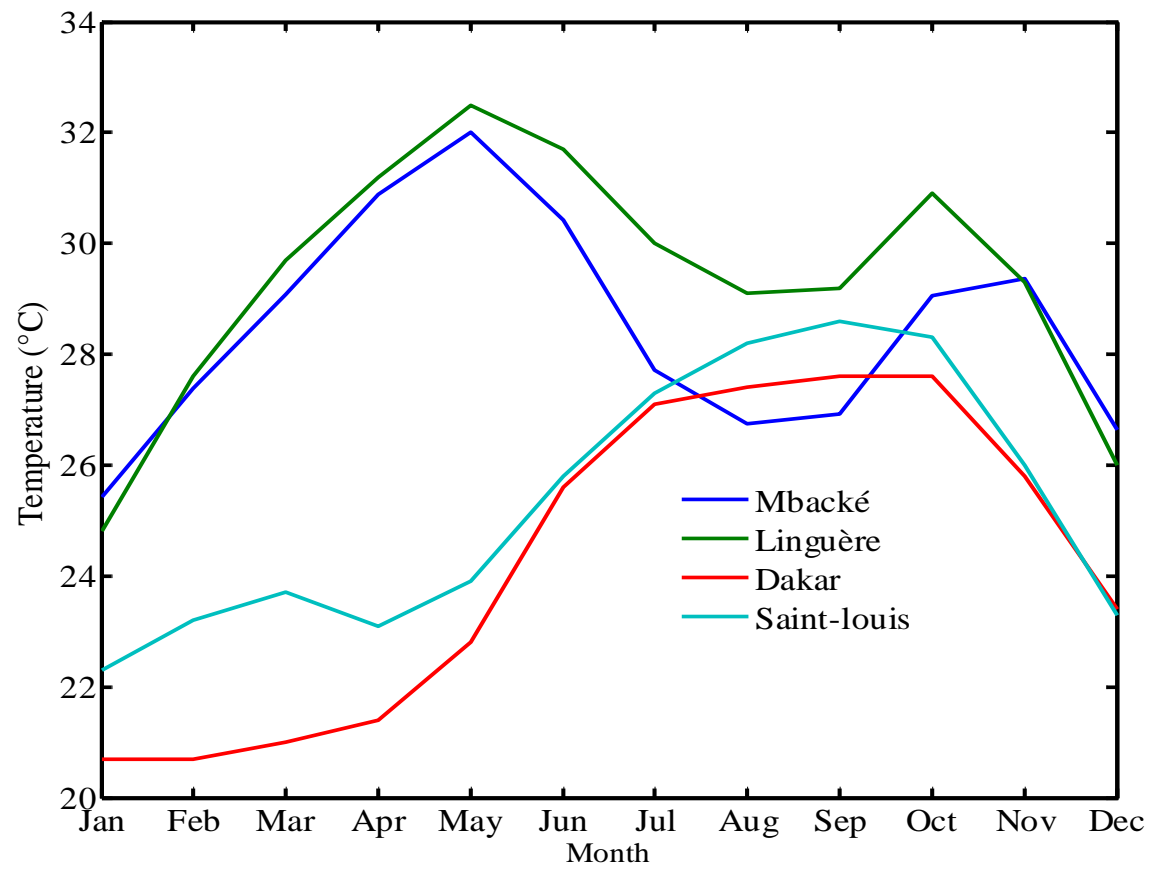

Figure 2. Evolution of the ambient temperature as a function of the month for different sites. 


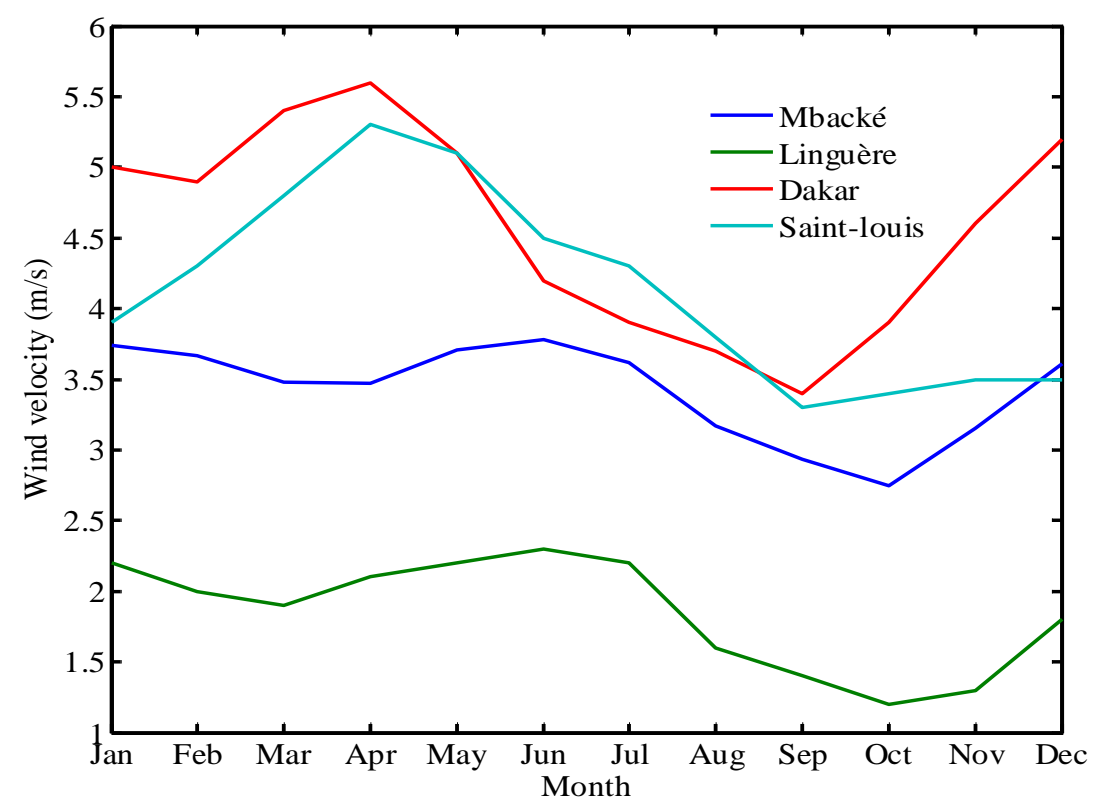

Figure 3. Evolution of wind speed as a function of the month for different sites.

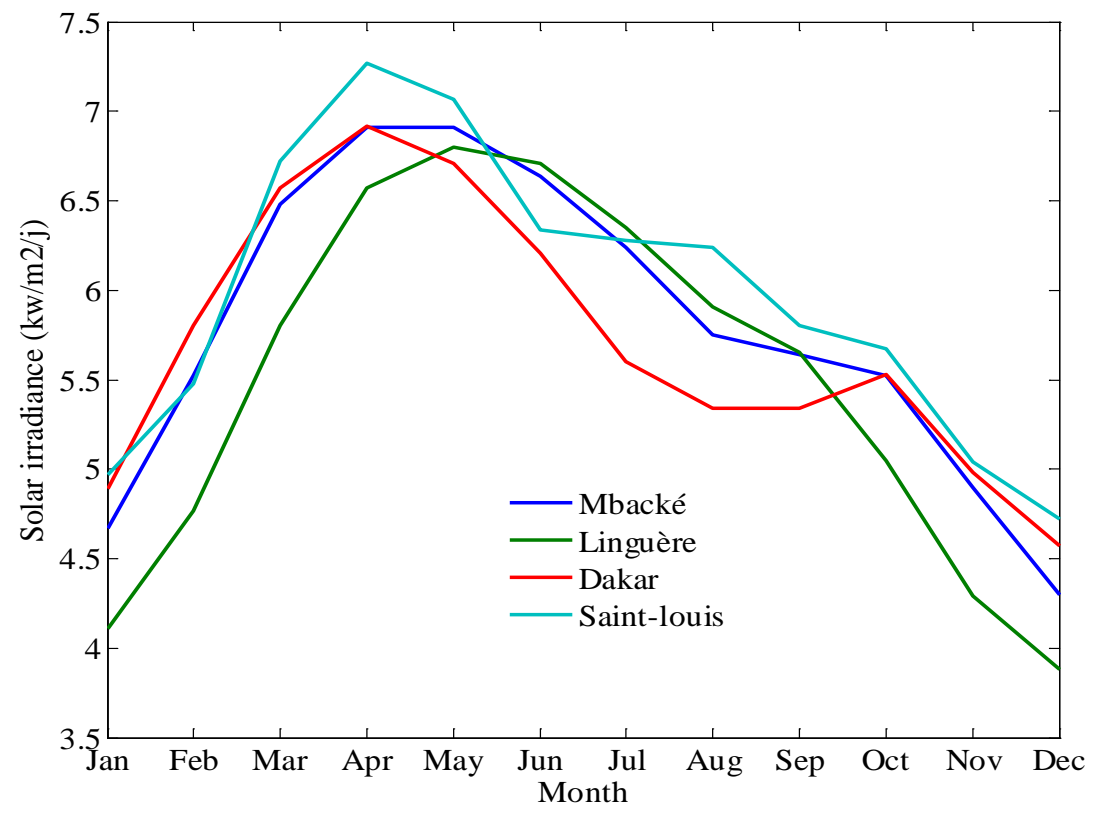

Figure 4. Evolution of the solar irradiation as a function of the month for different sites.

\section{Results and Discussion}

\subsection{Temperature of PV Modules}

The Faiman model given by Equation (1) is used to calculate the temperature of PV modules in different sites. The results obtained are shown in Figure 5. The temperature of the modules is higher in Linguère than elsewhere, and this throughout the year. The lowest temperatures of PV modules are recorded in Dakar throughout the year. It is noted that the temperature of PV modules is the lowest in the coastal zone. This is explained by the low ambient temperatures in 
this zone.

\subsection{Efficiency of PV Modules}

Figure 6 shows the module efficiency as a function of the month for Mbacké. The efficiency of PV modules is maximal in July. This period corresponds to the

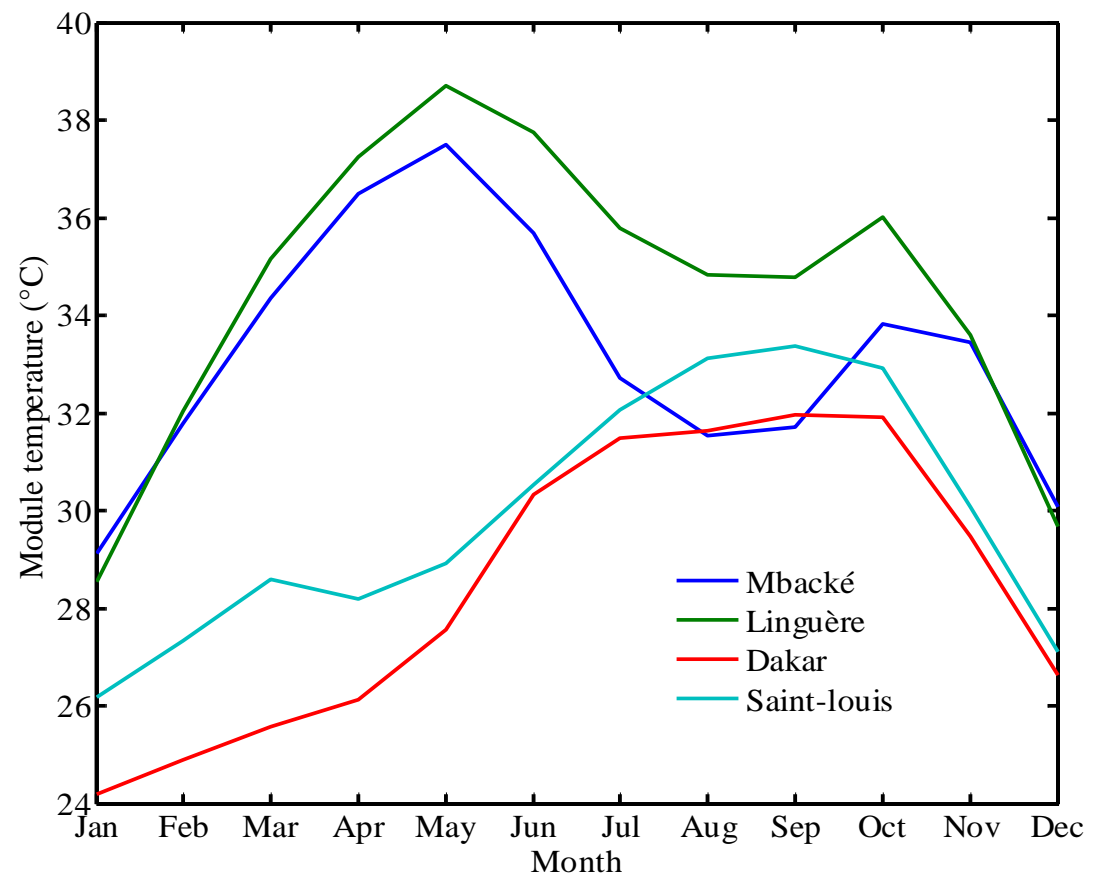

Figure 5. Evolution of the temperature of PV modules as a function of the month for different sites.

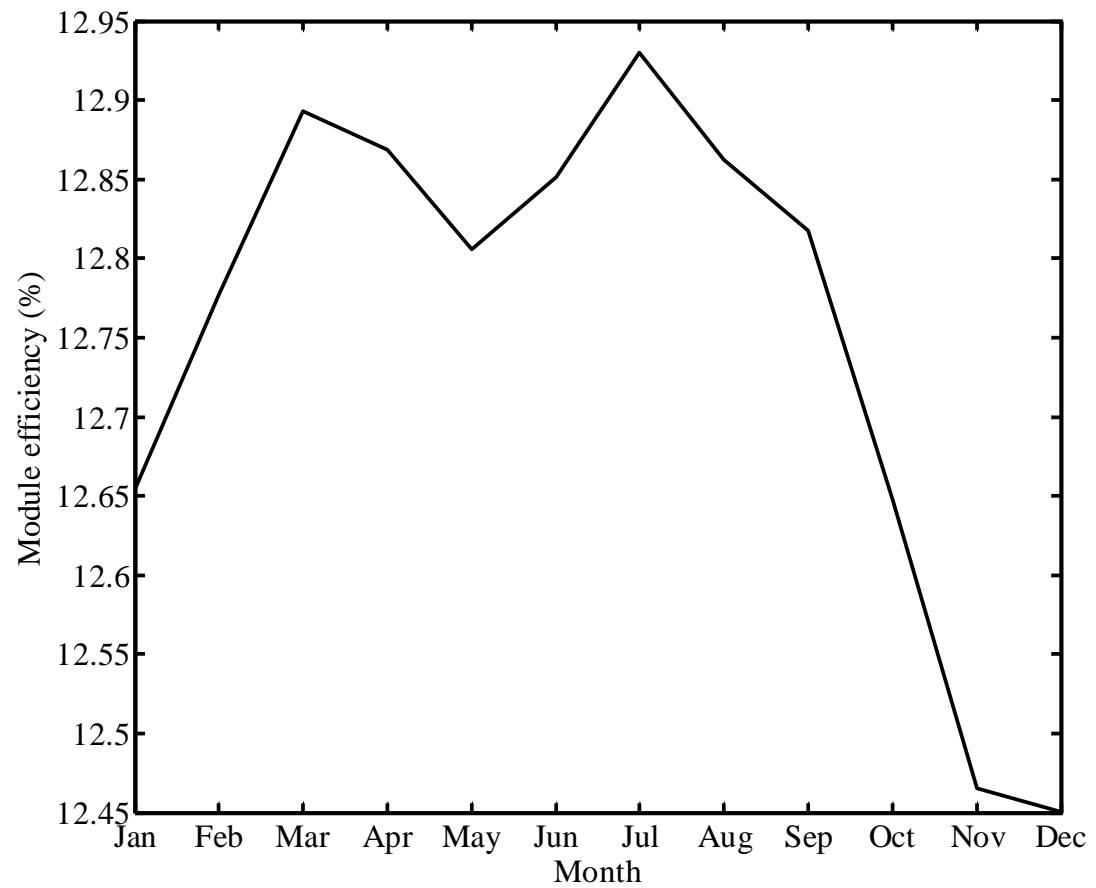

Figure 6. Evolution of module efficiency as a function of the month. 


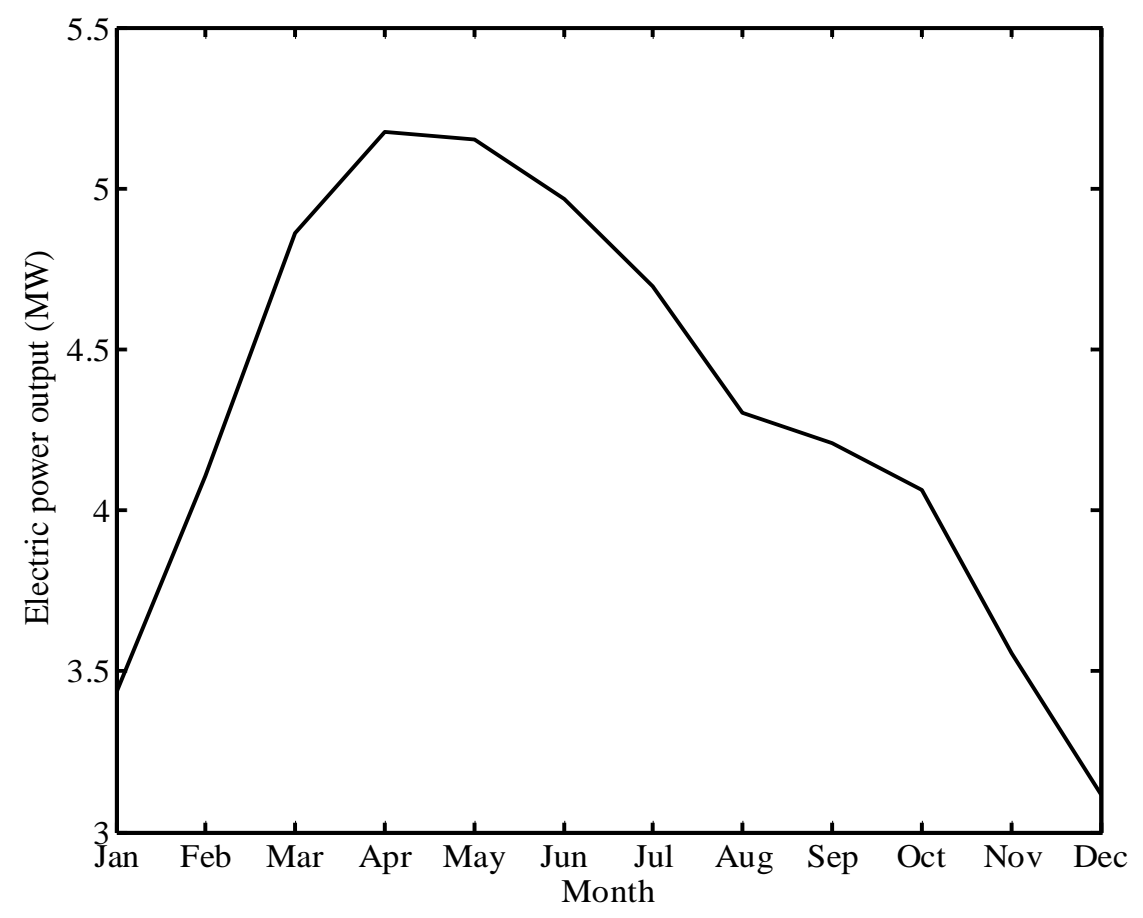

Figure 7. Evolution of electric power output as a function of the month.

rainy season. The ambient temperature is not very high. This positively affects the performance of PV modules.

Figure 7 shows the electrical power produced by the PV system as a function of the month for the Mbacké site. Electric power is maximum in April.

It is noted that maximum module efficiency and maximum electric power output are not obtained at the same time for the Mbacké site. This is due to strong solar irradiance in April and low solar irradiance in July.

\subsection{Assessment of the Impact of Climatic Conditions}

Figure 8 shows the module efficiency as a function of the month for the sites of Mbacké, Linguère, Dakar and Saint-Louis. The results show that from November to June, the module efficiency is higher in Dakar and Saint-Louis than in Mbacké and Linguère. From July to October the module efficiency is substantially equal in the four sites. This is due to improved indoor climatic conditions due to the rainy season from July to October in continental zone.

Figure 9 shows the electric power output as a function of the month for the sites of Mbacké, Linguère, Dakar and Saint-Louis. The results show that electric power is maximum in April for Mbacké, Dakar and Saint-Louis. For Linguère electric power is maximum in May.

The average electrical power supplied per month for the various sites is given in Table 2 . The results show that electricity production varies little from one site to another. Climatic conditions in Senegal therefore have little influence on electricity production. The importance and uniformity of solar radiation throughout Senegal hides the effect of climatic conditions on electricity production. 


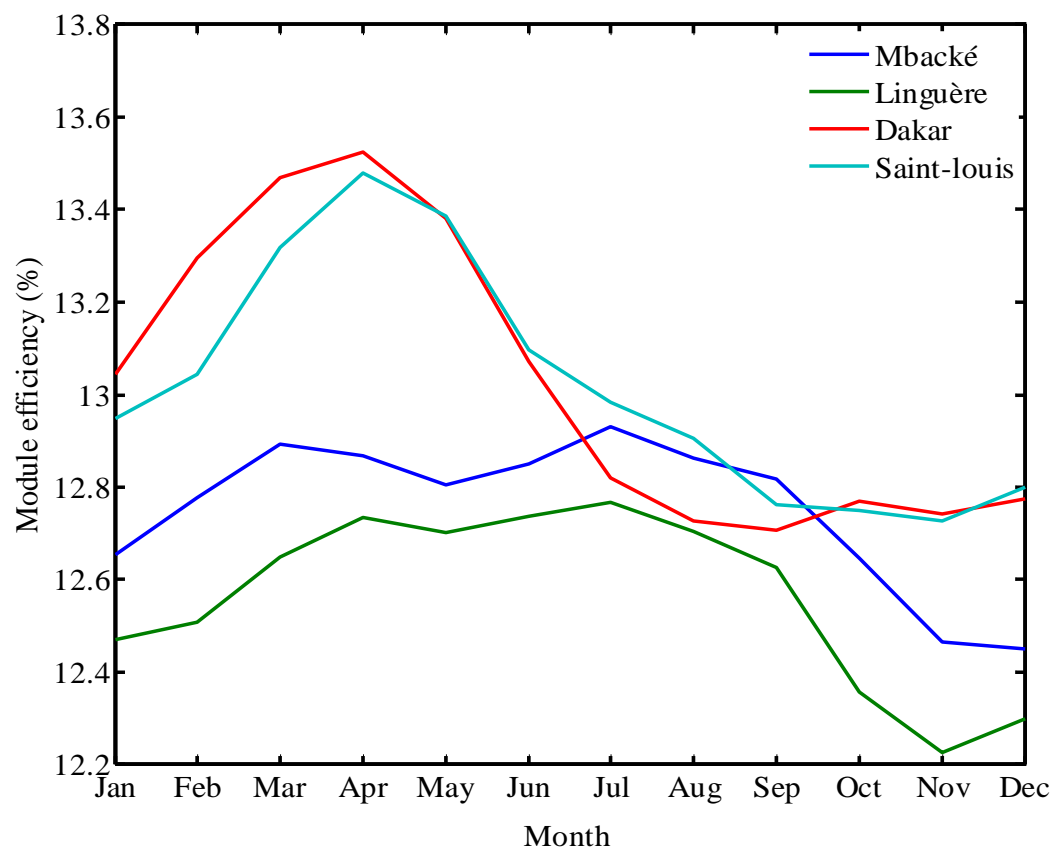

Figure 8. Evolution of module efficiency as a function of the month for different sites.

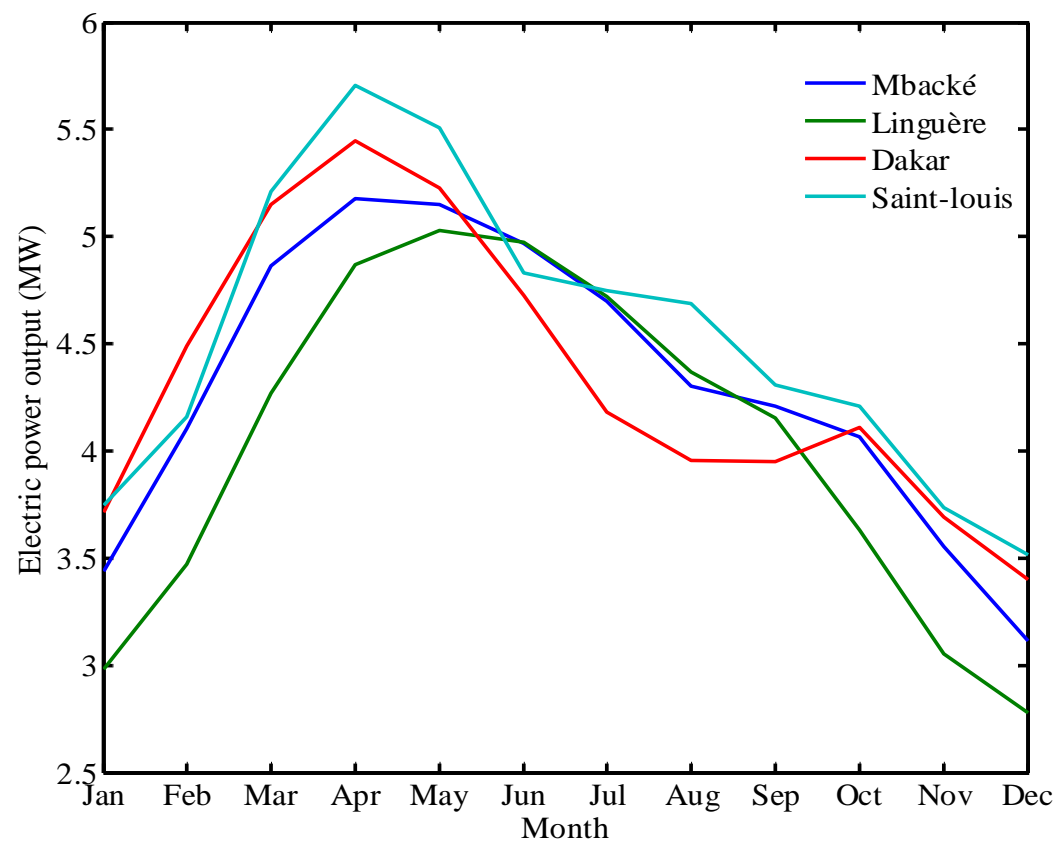

Figure 9. Evolution of electric power output as a function of the month for different sites.

Table 2. Average electrical power supplied per month.

\begin{tabular}{cc}
\hline Sites & Average electrical power supplied per month (MW) \\
\hline Mbacké & 4.3 \\
Linguère & 4.0 \\
Dakar & 4.3 \\
Saint-Louis & 4.5 \\
\hline
\end{tabular}




\section{Conclusion}

The purpose of this study is to analyze the performance of a photovoltaic solar power plant according to the installation site. The ambient temperature, the horizontal daily solar radiation, the wind speed were used to characterize the sites. The results obtained showed a significant difference between the climatic conditions of the coastal and continental zones. On the other hand, the solar radiation does not show a significant difference between the sites. All these factors make the efficiency of PV modules better on the coast, while electricity production varies little from one site to another. The results of this study also show that the irradiance is sufficiently high in Senegal to compensate for the loss of module output that occurs during the warm period.

\section{References}

[1] International Energy Agency (2014) https://www.iea.org/statistics/

[2] Mirzaei, P., Paterna, E. and Carmeliet, J. (2014) Investigation of the Role of Cavity Airflow on the Performance of Building-Integrated Photovoltaic Panels. Solar Energy, 107, 510-522. https://doi.org/10.1016/j.solener.2014.05.003

[3] Goverde, H., Goossens, D., Govaerts, J, Catthoor, F., Baert, K., Poortmans, J. and Driesen, J. (2017) Spatial and Temporal Analysis of Wind Effects on PV Modules: Consequences for Electrical Power Evaluation. Solar Energy, 147, 292-299. https://doi.org/10.1016/j.solener.2016.12.002

[4] Ye, Z., Nobre, A., Reindl, T., Luther, J. and Reise, C. (2013) On PV Module Temperatures in Tropical Regions. Solar Energy, 88, 80-87.

https://doi.org/10.1016/j.solener.2012.11.001

[5] Schwingshackl, C., Petitta, M., Wagner, J.E., Belluardo, G., Moser, D., Castelli, M., Zebisch, M. and Tetzlaff, A. (2013) Wind Effect on PV Module Temperature: Analysis of Different Techniques for an Accurate Estimation. Energy Procedia, 40, 77-86. https://doi.org/10.1016/j.egypro.2013.08.010

[6] Skoplaki, E. and Palyvos, J.A. (2009) On the Temperature Dependence of Photovoltaic Module Electrical Performance: A Review of Efficiency/Power Correlations. Solar Energy, 83, 614-624. https://doi.org/10.1016/j.solener.2008.10.008

[7] Rahmana, M.M., Hasanuzzaman, M. and Rahim, N.A. (2015.) Effects of Various Parameters on PV-Module Power and Efficiency. Energy Conversion and Management, 103, 348-358. https://doi.org/10.1016/j.enconman.2015.06.067

[8] Faiman, D. (2008) Assessing the Outdoor Operating Temperature of Photovoltaic Modules. Progress in Photovoltaics: Research and Applications, 16, 307-315. https://doi.org/10.1002/pip.813

[9] Barykina, E. and Hammer, A. (2017) Modeling of Photovoltaic Module Temperature Using Faiman Model: Sensitivity Analysis for Different Climates. Solar Energy, 146, 401-416. https://doi.org/10.1016/j.solener.2017.03.002

[10] Kaplani, E. and Kaplanis, S. (2014) Thermal Modelling and Experimental Assessment of the Dependence of PV Module Temperature on Wind Velocity and Direction, Module Orientation and Inclination. Solar Energy, 107, 443-460. https://doi.org/10.1016/j.solener.2014.05.037 